\title{
Suppression of Atlantic Meridional Overturning Circulation Variability at Increased $\mathrm{CO}_{2} \mathrm{O}$
}

\author{
DOUGLAS G. MACMARTIN \\ Computing and Mathematical Sciences, California Institute of Technology, Pasadena, California \\ LAURE ZANNA \\ Department of Physics, University of Oxford, Oxford, United Kingdom \\ ELI TZIPERMAN \\ Department of Earth and Planetary Sciences, and School of Engineering and Applied Sciences, \\ Harvard University, Cambridge, Massachusetts
}

(Manuscript received 29 July 2015, in final form 26 February 2016)

\begin{abstract}
Multidecadal variability in the Atlantic meridional overturning circulation (AMOC) is shown to differ significantly between the $4 \times \mathrm{CO}_{2}$ and preindustrial control simulations of the GFDL Earth System Model, version $2 \mathrm{M}$ (ESM2M) general circulation model (GCM). In the preindustrial simulation, this model has a peak in the power spectrum of both AMOC and northward heat transport at latitudes between $26^{\circ}$ and $50^{\circ} \mathrm{N}$. In the $4 \times \mathrm{CO}_{2}$ simulation, the only significant spectral peak is near $60^{\circ} \mathrm{N}$. Understanding these differences is important for understanding the effect of future climate change on climate variability, as well as for providing insight into the physics underlying AMOC variability. Transfer function analysis demonstrates that the shift is predominantly due to a shift in the internal ocean dynamics rather than a change in stochastic atmospheric forcing. Specifically, the reduction in variance from $26^{\circ}$ to $45^{\circ} \mathrm{N}$ is due to an increased stratification east of Newfoundland that results from the shallower and weaker mean overturning. The reduced AMOC variance that accompanies the reduced mean value of the AMOC at $4 \times \mathrm{CO}_{2}$ differs from predictions of simple box models that predict a weaker circulation to be closer to a stability bifurcation point and, therefore, be accompanied by amplified variability. The high-latitude variability in the $4 \times \mathrm{CO}_{2}$ simulation is related to the advection of anomalies by the subpolar gyre, distinct from the variability mechanism in the control simulation at lower latitudes. The $4 \times \mathrm{CO}_{2}$ variability has only a small effect on midlatitude meridional heat transport, but does significantly affect sea ice in the northern North Atlantic.
\end{abstract}

\section{Introduction}

Variability in the Atlantic meridional overturning circulation (AMOC) has been linked to variability in Atlantic sea surface temperatures and associated climate impacts (Kushnir 1994; Delworth and Mann 2000;

\footnotetext{
Supplemental information related to this paper is available at the Journals Online website: http://dx.doi.org/10.1175/JCLI-D-150533.s1.

Corresponding author address: Douglas G. MacMartin, Computing and Mathematical Sciences, California Institute of Technology, 1200 E. California Blvd., M/C 305-16, Pasadena, CA 91125. E-mail: macmardg@cds.caltech.edu
}

Knight et al. 2005; O'Reilly et al. 2016). There has been a significant number of studies aimed at understanding model-simulated AMOC variability in preindustrial or current climate conditions (Delworth et al. 1993; Greatbatch and Zhang 1995; Yeager and Danabasoglu 2012); see also the recent review by Buckley and Marshall (2016). Several GCMs yield strong multidecadal peaks in the power spectrum of AMOC variability under preindustrial conditions (e.g., MacMartin et al. 2013; Muir and Fedorov 2015), which correspond to significant autocorrelation and hence potentially useful predictability (e.g., Griffies and Bryan 1997). This variability may be interpreted as either selfsustained variability (e.g., te Raa et al. 2004) or as the result of a relatively lightly damped system excited by broadband atmospheric "noise" (Griffies and Tziperman 1995). 

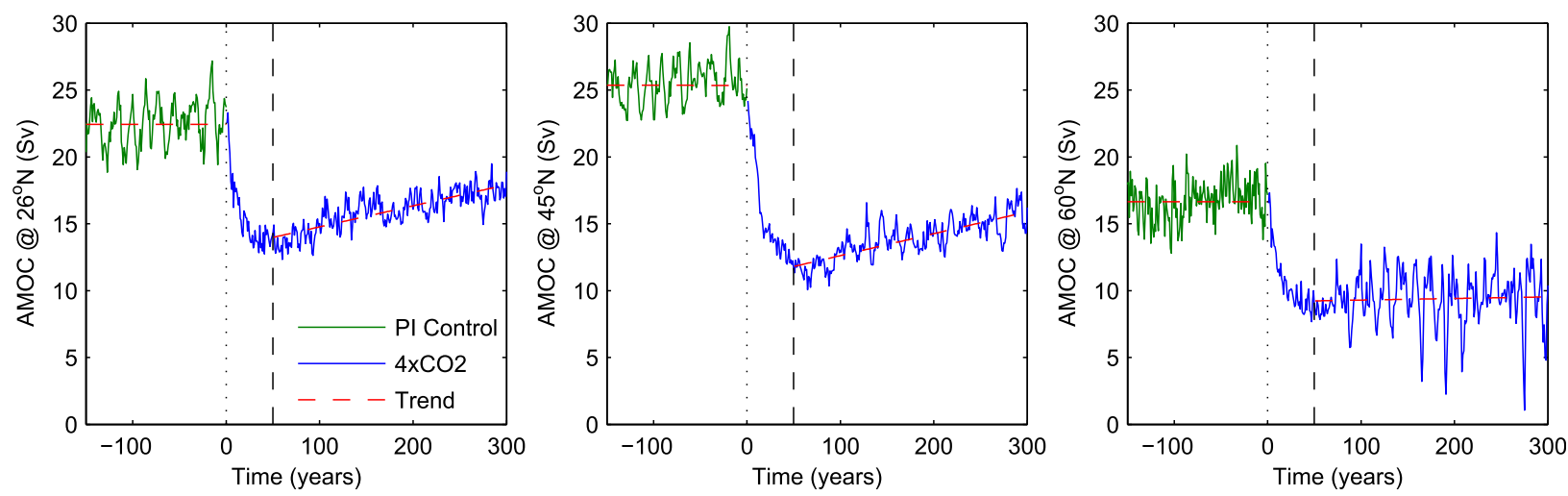

FIG. 1. AMOC strength at $26^{\circ}, 45^{\circ}$, and $60^{\circ} \mathrm{N}$ in the abrupt $4 \times \mathrm{CO}_{2}$ simulation for GFDL ESM2M. The final 150 years of the preindustrial simulation are also shown for comparison $\left(4 \times \mathrm{CO}_{2}\right.$ starts in year zero of the plots). To minimize the impact of the initial transient, the first 50 years of the $4 \times \mathrm{CO}_{2}$ simulation are discarded, and all subsequent analyses are conducted after removing the trend of the remaining 250 years (indicated on the plots with dashed lines). The full time series for the preindustrial control is shown in Fig. S1; the mean value of AMOC at $26^{\circ}, 45^{\circ}$, and $60^{\circ} \mathrm{N}$ in the control simulation is $22.4,25.4$, and $16.6 \mathrm{~Sv}\left(1 \mathrm{~Sv} \equiv 10^{6} \mathrm{~m}^{3} \mathrm{~s}^{-1}\right)$, respectively.

However, there has been less attention to how this variability might be altered by anthropogenic climate change, and this is the purpose of the present work. The theoretical framework introduced by the Stommel (1961) box model has been used to speculate that because the mean AMOC is expected to weaken under increased $\mathrm{CO}_{2}$ forcing (e.g., Stocker and Schmittner 1997; Cheng et al. 2013; Collins et al. 2013), it would shift closer to a bifurcation point (Tziperman et al. 1994; Tziperman 1997). If so, then the AMOC variance ought to increase (Wiesenfeld and McNamara 1986; Ditlevsen and Johnsen 2010); this has even been explored as a possible precursor to detect bifurcation (Lenton 2011; Lenton et al. 2012). However, it remains unclear whether this indeed is the case. Results for CMIP5 models, for example, are shown in Fig. 12.35 of Collins et al. (2013) and in Fig. 1b of Cheng et al. (2013), where there is arguably decreased variability in several models as $\mathrm{CO}_{2}$ increases. Both of these studies consider only AMOC at $30^{\circ} \mathrm{N}$. We focus here on the GFDL Earth System Model, version 2M (ESM2M) GCM, and compare AMOC variability between preindustrial and abrupt $4 \times \mathrm{CO}_{2}$ simulations to better understand changes in AMOC variability across a range of latitudes under increased atmospheric $\mathrm{CO}_{2}$ concentrations.

Midlatitude preindustrial AMOC variability is dominated by thermohaline dynamics in this GCM. We show that this midlatitude AMOC variability is suppressed at higher $\mathrm{CO}_{2}$, and is replaced by a limited-area high-latitude AMOC variability that is driven by horizontal advection in the subpolar gyre. We also show that the decrease in midlatitude variability at higher $\mathrm{CO}_{2}$ is due to an increased midlatitude ocean stratification in part due to the weakened overturning. Finally, we show that our results are not consistent with what might be expected from the above-mentioned simple and commonly used thermohaline box models, as over the (nonequilibrium) time horizon considered here the GFDL ESM2M GCM responds to the increased $\mathrm{CO}_{2}$ concentration with a decrease in both the mean AMOC and its variability.

\section{Model simulations}

We use 500 years of a preindustrial control simulation and 300 years of an abrupt $4 \times \mathrm{CO}_{2}$ simulation of the GFDL ESM2M GCM (Dunne et al. 2012). The AMOC time series from a $1 \% \mathrm{yr}^{-1}$ increase in $\mathrm{CO}_{2}$ $\left(1 \% \mathrm{CO}_{2}\right)$ simulation are also shown in Fig. S2 in the supplementary material to illustrate that the suppression of midlatitude variability is not a result of the abrupt nature of the $\mathrm{CO}_{2}$ increase. Since the $1 \% \mathrm{CO}_{2}$ simulation is far from a quasi equilibrium, we focus on the abrupt $4 \times \mathrm{CO}_{2}$ case for the remainder of the analysis. For the $4 \times \mathrm{CO}_{2}$ simulation we analyze only the last 250 years of the 300 -yr simulation to avoid most of the initial transient response. However the abyssal ocean has not completely equilibrated over this time horizon (see Fig. 1), and previous results have indicated the possibility of continued changes in the mean AMOC over longer time scales (Stouffer and Manabe 2003) consistent with the trend shown in Fig. 1. The simulation is thus not directly comparable to the equilibrium response of box models.

Our purpose is to present an interesting mechanism for the suppression of AMOC variability rather than estimate the likelihood of such a suppression, and we therefore focus on the analysis of a single model rather than examine, for example, multiple CMIP models as was done in MacMartin et al. (2013). This focus on a single model also allows an in-depth analysis of several $3 \mathrm{D}$ model fields, for two $\mathrm{CO}_{2}$ values, which is not 
(a)
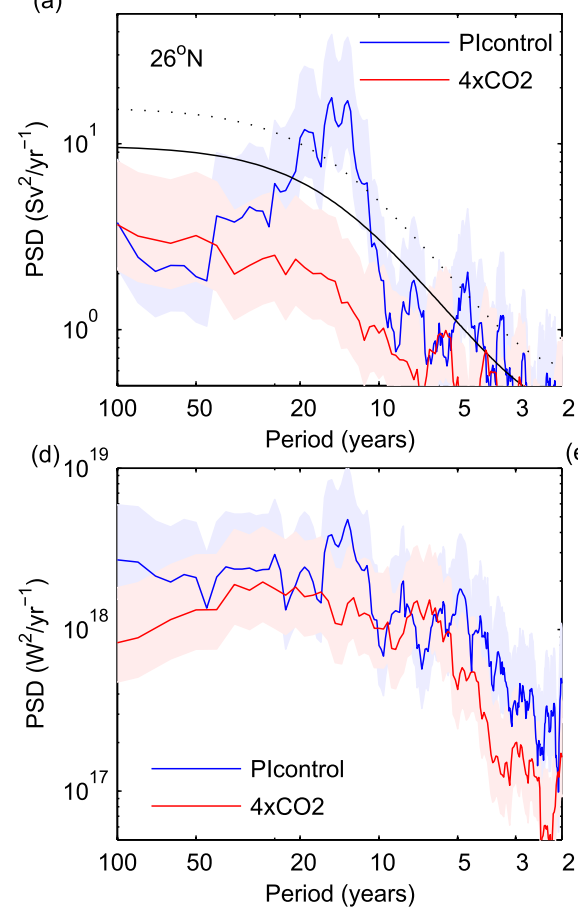

(b)

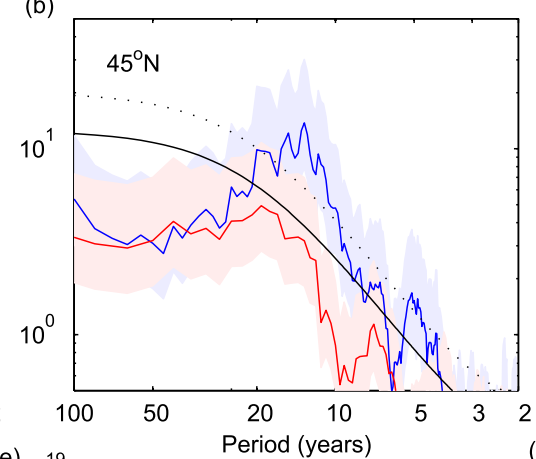

(e) $10^{19}$

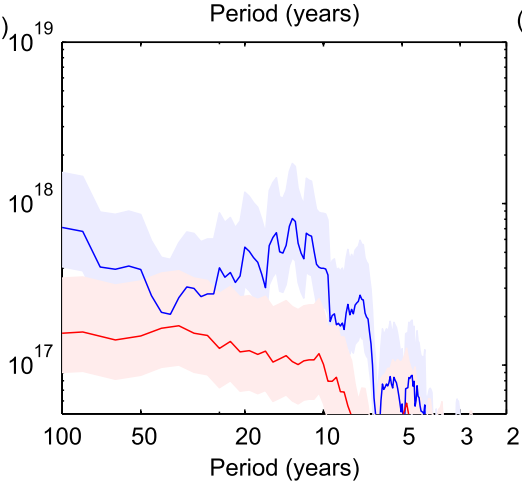

(c)

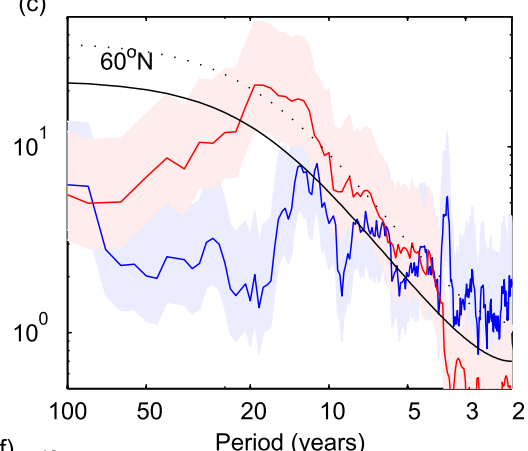

(f) $10^{19}$

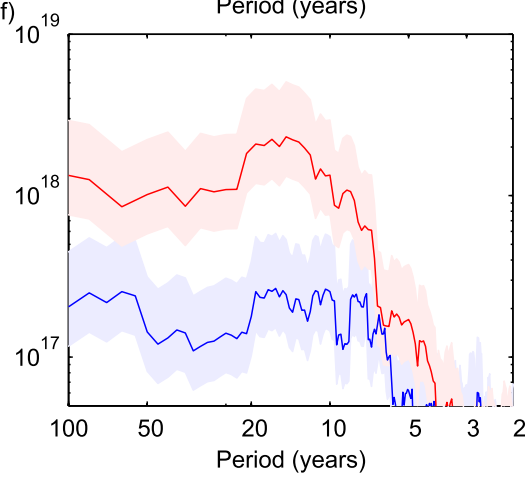

FIG. 2. Power spectrum of AMOC variability at (a) $26^{\circ}$, (b) $45^{\circ}$, and (c) $60^{\circ} \mathrm{N}$, for preindustrial control simulation (blue, 500 years), and $4 \times \mathrm{CO}_{2}$ (red, last 250 years of a 300-yr simulation); shaded bands represent $95 \%$ confidence intervals. Also shown is a variance-equivalent red-noise (AR1) spectrum (black lines) and corresponding 95\% confidence level (dotted), to test statistical significance of the spectral peaks. This is plotted only for the preindustrial simulation for $26^{\circ}$ and $45^{\circ} \mathrm{N}$ and only for the $4 \times \mathrm{CO}_{2}$ simulation for $60^{\circ} \mathrm{N}$. (d)-(f) The power spectrum of northward heat transport at the same latitudes is shown; only the "overturning" heat transport component is shown (Bryan 1982; Johns et al. 2011).

straightforward to present for multiple models. There are two reasons for focusing on GFDL ESM2M in particular. First, this model exhibits a strong spectral peak in AMOC variability, which is of particular interest both because this potentially increases decadal predictability (Msadek et al. 2010), and because it is consistent with a lightly damped system where changes in stability with rising $\mathrm{CO}_{2}$ could be important. And second, the $4 \times \mathrm{CO}_{2}$ simulation is long enough to explore the dynamics after many of the initial transients have settled, allowing us to explore the AMOC variability changes in a higher $\mathrm{CO}_{2}$ world. We choose a rather strong $4 \times \mathrm{CO}_{2}$ increase scenario in order to maximize the signal-to-noise ratio in the model response.

\section{Characteristics of the variability}

At each latitude, the AMOC strength is calculated as the maximum over depth of the streamfunction. [All analyses are conducted with the Ekman component of the meridional streamfunction removed as in Hirschi and Marotzke (2007), although this has a negligible influence at the latitudes considered here.] As expected, the mean AMOC is substantially weaker in the greenhouse warming scenario relative to the preindustrial control simulation (Fig. 1). In both simulations, the highest midlatitude mean overturning circulation occurs at $45^{\circ} \mathrm{N}$ (see Figs. 3b,e described below).

The power spectrum of the AMOC at selected latitudes is shown in Figs. 2a-c. For the preindustrial simulation, at latitudes between $26^{\circ}$ and $50^{\circ} \mathrm{N}$ the power spectrum of AMOC variability exhibits a statistically significant peak, relative to a red-noise hypothesis, with a period of about 15 years. However, in the $4 \times \mathrm{CO}_{2}$ scenario, there is no spectral peak at $26^{\circ} \mathrm{N}$ (roughly the latitude of the RAPID array; Cunningham et al. 2007; McCarthy et al. 2012), and the only strong (statistically significant) spectral peak is farther north near $60^{\circ} \mathrm{N}$ (Fig. 2). The advective northward heat transport due to the overturning circulation component is calculated as in Bryan (1982) and Johns et al. (2011) and the associated power spectrum is shown in Figs. 2d,f. The heat transport spectrum is broadly similar to that of AMOC although the spectral peaks are less prominent. While the preindustrial AMOC variability leads to significant variability in midlatitude heat transport, the high-latitude AMOC variability in the $4 \times \mathrm{CO}_{2}$ simulation only impacts the relatively smaller heat transport north of $55^{\circ} \mathrm{N}$. The mean 

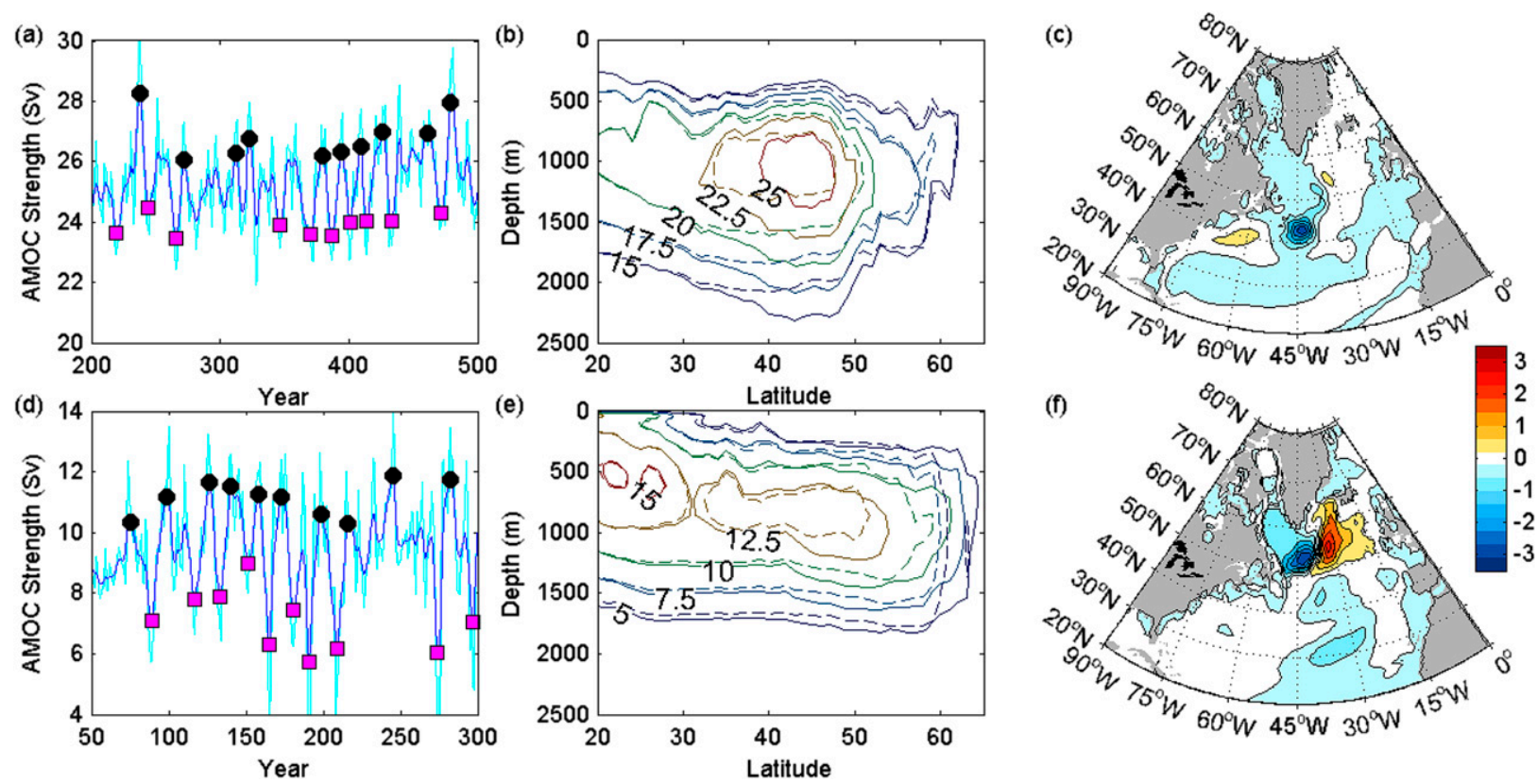

FIG. 3. Composite pattern of AMOC variability for (top) preindustrial control and (bottom) at $4 \times \mathrm{CO}_{2}$. (left) AMOC time series is shown, with a darker line filtered at a 5 -yr time scale to smooth high-frequency variability: (a) preindustrial control at $45^{\circ} \mathrm{N}$ and (d) $4 \times \mathrm{CO}_{2}$ at $60^{\circ} \mathrm{N}$. Composite maps are created from the average over selected years when AMOC is at a maximum (black circles) minus the average over selected years when AMOC is at a minimum (magenta squares). The resulting composite map of the overturning streamfunction is shown in the center column (in Sv), contours at maximum and minimum shown with solid and dashed lines, respectively]: (b) for preindustrial and (e) for $4 \times \mathrm{CO}_{2}$. The difference between ocean temperature averaged over the upper $1000 \mathrm{~m}$ at AMOC maxima and minima $\left({ }^{\circ} \mathrm{C}\right)$ is shown for (c) preindustrial and (f) for $4 \times \mathrm{CO}_{2}$.

overturning circulation in the $4 \times \mathrm{CO}_{2}$ simulation is strongest from $20^{\circ}$ to $50^{\circ} \mathrm{N}$, therefore the higher-latitude variability does not substantially affect the maximum overturning, nor the ocean heat transport south of roughly $55^{\circ} \mathrm{N}$. This northward shift in AMOC variability at high $\mathrm{CO}_{2}$ could thus provide a mechanism by which anthropogenic climate change could affect midlatitude climate variability.

The pattern of the variability associated with the spectral peak in both simulations can be examined by creating a composite pattern averaged over years during which the AMOC is at a maximum, minus years when the AMOC is at a minimum, as illustrated in Fig. 3. For the preindustrial case, we construct a composite based on selected maxima and minima of $\mathrm{AMOC}$ at $45^{\circ} \mathrm{N}$, while for the $4 \times \mathrm{CO}_{2}$ simulation we use AMOC at $60^{\circ} \mathrm{N}$ where the variability is strongest in order to better understand the high-latitude variability that arises in this case. For each simulation, the AMOC index is first filtered at a 5-yr period to focus on decadal variability, and the 10 most prominent maxima and minima in each simulation are retained for constructing composites (prominence relative to neighboring minima or maxima).

Figures $3 \mathrm{~b}$,e show the streamfunction averaged over times of AMOC maxima (solid lines) and separately averaged over times of minima (dashed lines). The preindustrial AMOC variability is characterized by changes in the strength, the latitude, and the depth of the circulation as shown in Figs. 3a,b, and is associated with variability in upper ocean heat content (Fig. 3c) and heat transport (Fig. 2). The preindustrial AMOC variability involves changes in maximum overturning strength and depth at $40^{\circ}-50^{\circ} \mathrm{N}$ (Fig. 3b) as well as a slight northward shift of the streamfunction near $50^{\circ} \mathrm{N}$. The AMOC variability in the $4 \times \mathrm{CO}_{2}$ case (Fig. 3e) primarily involves a local variability in the northernmost extent of the overturning cell beyond $60^{\circ} \mathrm{N}$, well north of the latitude of peak overturning circulation, rather than modulations to its maximum value at midlatitudes. This explains the relatively minor impact of the $4 \times \mathrm{CO}_{2}$ AMOC variability on midlatitude northward heat transport. The patterns of upper ocean heat content anomalies associated with the AMOC variability in both simulations (Figs. 3c,f) illustrate that the variability in these anomalies is also shifted northward in the $4 \times \mathrm{CO}_{2}$ simulation.

Lag-correlation analysis shown in Fig. 4a indicates that in the preindustrial case, the spectral peak is consistent with a thermohaline oscillation (Delworth et al. 1993; Griffies and Tziperman 1995), where the temperature and salinity in the sinking region $\left(45^{\circ}-65^{\circ} \mathrm{N}\right)$ play 

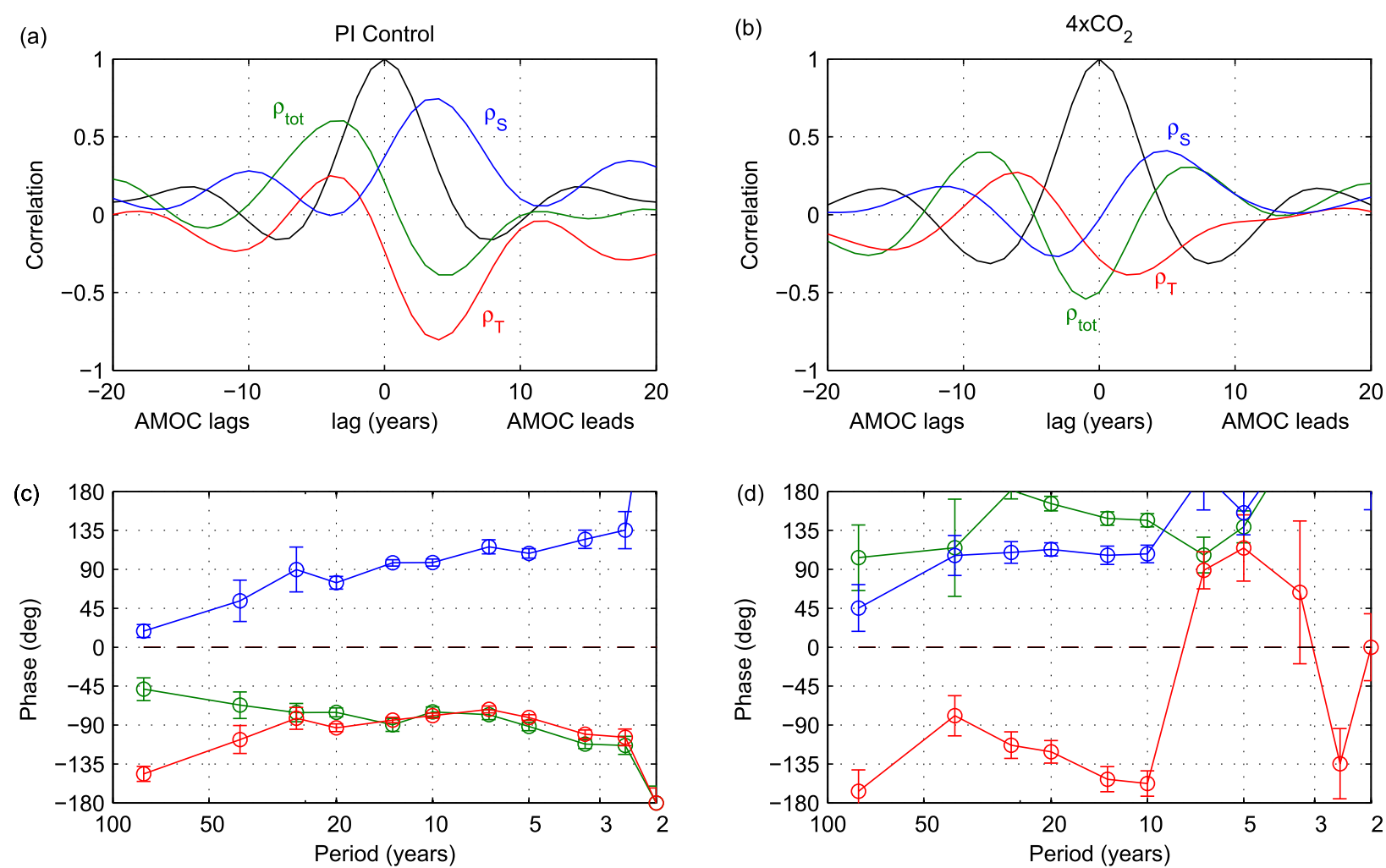

FIG. 4. Temperature-salinity phase relations characterizing AMOC variability are different in (left) preindustrial control and (right) $4 \times \mathrm{CO}_{2}$ simulations. (top) The lag-correlation plot (AMOC leads at positive lag) relating AMOC to itself (black line), to high-latitude density (green, $\rho_{\text {tot }}$ ), density due to temperature perturbations (red, $\rho_{T}$ ), and density due to salinity perturbations (blue, $\rho_{S}$ ); all variables are filtered at a 5 -yr period to focus on decadal variability. The phase relationships are clearer from transfer function analysis. (bottom) The phase of the transfer function relating each variable to AMOC (AMOC leads at positive phase). For the preindustrial simulation (c) the lead or lag phase relationships (roughly $1 / 4$ cycle, $\pm 90^{\circ}$ ) are maintained across a range of frequencies, and net density anomalies lead AMOC changes. (d) For the $4 \times \mathrm{CO}_{2}$ simulation, the density now lags AMOC, as do temperature anomalies at higher frequencies (shorter periods). Temperature and salinity are averaged over the sinking region of $45^{\circ}-65^{\circ} \mathrm{N}$ and upper $1000 \mathrm{~m}$ in both cases. Results for preindustrial are calculated based on correlation with $\mathrm{AMOC}$ at $45^{\circ} \mathrm{N}$ and for $4 \times \mathrm{CO}_{2}$ with $\mathrm{AMOC}$ at $60^{\circ} \mathrm{N}$. $(\mathrm{See}$ also Fig. S3 in the supplemental material where the $4 \times \mathrm{CO}_{2}$ relationships are calculated with $\mathrm{AMOC}$ at $45^{\circ} \mathrm{N}$.)

distinctly independent roles and lag one another as anticipated by a simple linearized box model (Griffies and Tziperman 1995). This result is equivalent to Fig. 8 in Delworth et al. (1993) for an earlier version of the GFDL model, where here we have slightly adjusted the sinking region used in the calculation, consistent with the mean streamfunction for the current simulation. Transfer function analysis (MacMynowski and Tziperman 2010; MacMartin et al. 2013, and supplementary material) in Fig. $4 \mathrm{c}$ complements this finding by showing that the phase relationship between variables is consistent across a range of frequencies: temperature and density anomalies lead AMOC by $1 / 4$ cycle $\left(90^{\circ}\right)$, while salinity anomalies lag AMOC by $1 / 4$ cycle, not just at the spectral peak that dominates the calculation of correlation, but across a wide frequency band.

Figures $4 \mathrm{~b}, \mathrm{~d}$ evaluate the same relationships relative to AMOC variability at $60^{\circ} \mathrm{N}$ in the $4 \times \mathrm{CO}_{2}$ simulation, in order to explore whether or not the oscillatory behavior that arises there is due to the same mechanism as in the preindustrial case. As noted earlier, the mean sinking region associated with the mean overturning circulation does not shift northward in the increased $\mathrm{CO}_{2}$ simulation. We thus consider the same $45^{\circ}-65^{\circ} \mathrm{N}$ sinking region. Compared to the preindustrial case, the phase relationships for the $4 \times \mathrm{CO}_{2}$ case (Figs. $4 \mathrm{~b}, \mathrm{~d}$ ) are fairly distinct, indicating that the dynamics are different from those of the preindustrial simulation of the same model. This is clearest in the transfer function phase (Fig. 4d), which indicates that temperature and salinity still lead and lag AMOC, respectively, though not at all frequencies, while the net density anomalies now lag AMOC variability. Evaluating these relationships in the $4 \times \mathrm{CO}_{2}$ simulation for $\mathrm{AMOC}$ at $45^{\circ} \mathrm{N}$ yields roughly similar results (see Fig. S3 in the supplementary material). 
(a)

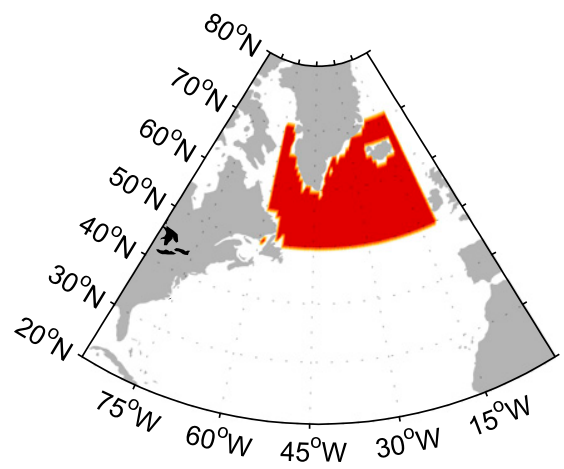

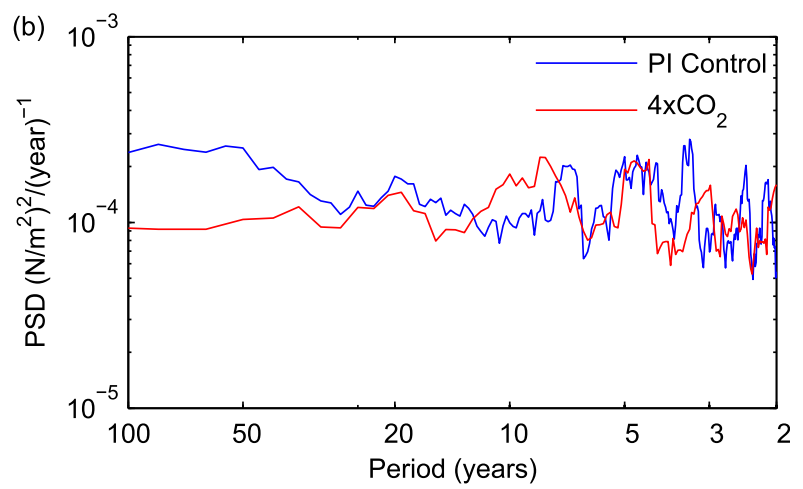
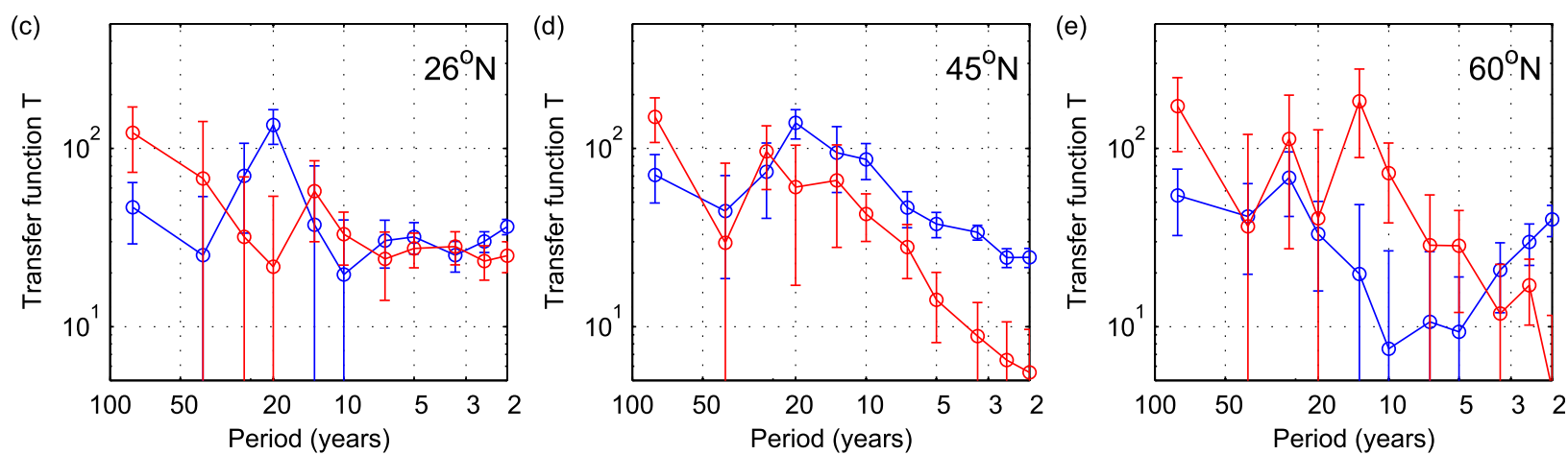

FIG. 5. Indication that difference in AMOC variability between preindustrial and greenhouse scenario is due to different dynamics rather than due to different atmospheric forcing. (a) The region over which the wind stress is averaged; (b) the corresponding power spectrum and the transfer function ( $\mathrm{Sv}$ per $\mathrm{N} \mathrm{m}^{-2}$ ) to AMOC variability at (c) $26^{\circ}$, (d) $45^{\circ}$, and (e) $60^{\circ} \mathrm{N}$, for both the preindustrial control (blue) and $4 \times \mathrm{CO}_{2}$ simulations (red). Error bars show \pm 1 standard deviations of the error estimate on the transfer function magnitude, to give an approximate visual indication of statistical significance from where error bars do not overlap. Using a Student's $t$ test, the differences in transfer function magnitude at 20 -yr period $\left(26^{\circ}\right.$ and $\left.45^{\circ} \mathrm{N}\right)$ or 15 -yr period $\left(60^{\circ} \mathrm{N}\right)$ are statistically significant at the $95 \%$ level. The power spectrum indicates that the external stochastic forcing is similar, while the transfer functions show that the dynamic response to this forcing differs between the two simulations.

\section{Mechanisms}

We next examine whether the different AMOC behavior in the two simulations considered is due to a difference in the atmospheric forcing or in the ocean dynamics. MacMartin et al. (2013) found the response to high-latitude surface fluxes to be a key factor in distinguishing between those models with a spectral peak in AMOC variability and those without. Stochastic forcing from high-latitude wind stress in particular had a clear role in exciting multidecadal AMOC variability, while for other surface fluxes such as buoyancy forcing, distinguishing cause and effect is less clear. Figure $5 b$ shows the power spectrum of high-latitude wind stress to be similar for the two simulations. More important is the transfer function between the high-latitude wind stress and the AMOC at $26^{\circ}, 45^{\circ}$, and $60^{\circ} \mathrm{N}$, shown in Figs. $5 \mathrm{c}$, d,e for the preindustrial (blue lines) and the $4 \times \mathrm{CO}_{2}$ simulation (red lines). These transfer functions represent the dynamical ocean responses to the atmospheric forcing, and are notably different between the two simulations, particularly at time scales of 10-20 years associated with the AMOC spectral peak (Fig. 2). While the shorter time series available for the $4 \times \mathrm{CO}_{2}$ case results in larger error bars in transfer function estimates, the differences between the two simulations are nonetheless larger than the estimation errors. We conclude that the shift in the characteristics of the AMOC variability is not due to a change in atmospheric stochastic forcing. We will show next that the change in AMOC variability is due to a change in the underlying ocean dynamics.

Specifically, the reduced midlatitude variability in the $4 \times \mathrm{CO}_{2}$ simulations can be explained by a change in background ocean stratification. Composite maps of the 1000-m vertical velocity (corresponding to the depth of the maximum AMOC; Figs. 3b,e) are shown in Fig. 6 at times of maxima and minima of the MOC index, along with the Brunt-Väisälä frequency for 

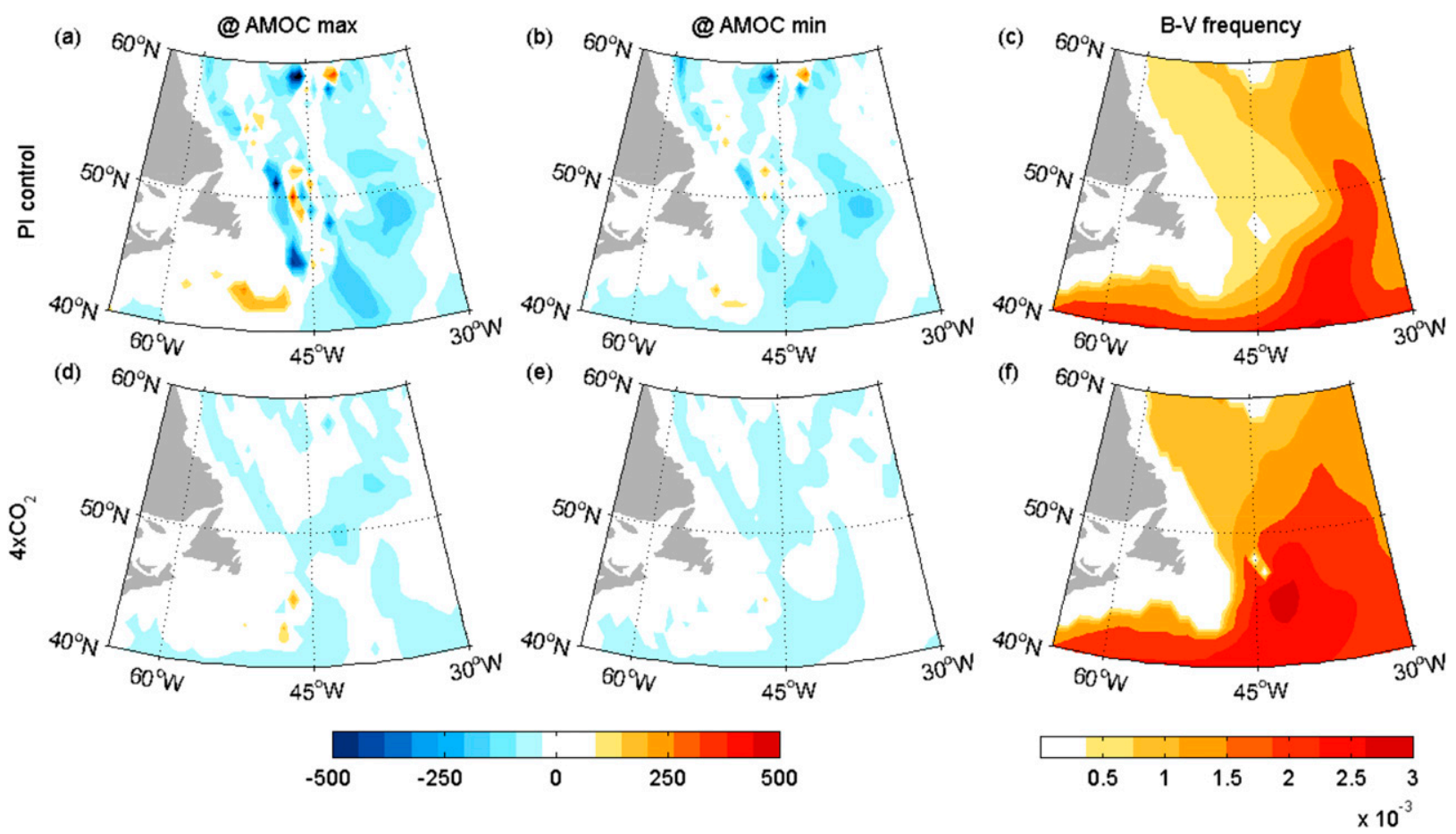

FIG. 6. Vertical mass transport $\left(\mathrm{kg} \mathrm{s}^{-1}\right)$ at $1000 \mathrm{~m}$ averaged over years of AMOC (a),(d) maxima and (b),(e) minima for (top) preindustrial control and (bottom) $4 \times \mathrm{CO}_{2}$. The maxima/minima are defined as in Figs. 3a,d. (c),(f) The mean Brunt-Väisälä frequency (s ${ }^{-1}$ ) at 1000-m depth for each simulation; while stratification is not uniformly increased, there is a significant increase east of the Grand Banks in particular where there was large variation in the vertical velocity in the preindustrial simulation.

preindustrial and $4 \times \mathrm{CO}_{2}$ simulations. In the preindustrial simulation, the oscillation in overturning circulation is primarily associated with variability in vertical velocity that is spatially localized east of the Grand Banks. The variability in vertical velocity at this location is mostly due to cross-isopycnal flow, with the variability in the along-isopycnal component about 4 times smaller [see Fig. 7; the vertical velocity along the isopycnal is calculated as $u(\partial \rho / \partial x) /(\partial \rho / \partial z)+v(\partial \rho / \partial y) /(\partial \rho / \partial z)]$. As the surface ocean warms due to the increased atmospheric $\mathrm{CO}_{2}$, this warming signal propagates downward (as a reduction in upward heat transport) to 1000-m depth due to the mean overturning circulation. This in turn results in decreased upper ocean density and increased stratification, particularly in areas where the sinking velocity was highest in the preindustrial simulation. The increased stratification inhibits further mixing and damps cross-isopycnal velocities that are a critical part of the AMOC variability. The midlatitude AMOC variability is thus reduced at $4 \times \mathrm{CO}_{2}$ over the multicentury time scales considered here.

The above finding is in contrast to expectations from box models, although there are a number of differences between the scenario here and that typically considered in box models: the result here is not for an equilibrated deep ocean, and the dominant forcing that weakens the mean AMOC strength is from heat fluxes rather than freshwater flux (Gregory et al. 2005). Box models suggest that as freshwater forcing at increased $\mathrm{CO}_{2}$ weakens the mean AMOC, the circulation is brought closer to a bifurcation point where the circulation becomes unstable and may collapse (Tziperman et al. 1994). Being closer to this bifurcation point implies that the less-damped AMOC ought to give rise to increased variance (e.g., Ditlevsen and Johnsen 2010; Lenton 2011). While it has been shown that a previous generation version of the GFDL model becomes unstable at weaker mean AMOC (Tziperman 1997), this does not seem to be the case in the simulations examined here: the mean AMOC is weakened at $4 \times \mathrm{CO}_{2}$, but the variance in midlatitude does not increase. One likely reason for this difference is that the MOC in box models (e.g., Stommel 1961) used to make these predictions does not depend on the vertical stratification, but only on the large-scale meridional density gradients, while here the midlatitude AMOC variability has decreased at $4 \times \mathrm{CO}_{2}$ because of the increased vertical stratification accompanying the change in mean circulation. A partial AMOC recovery in subsequent centuries 


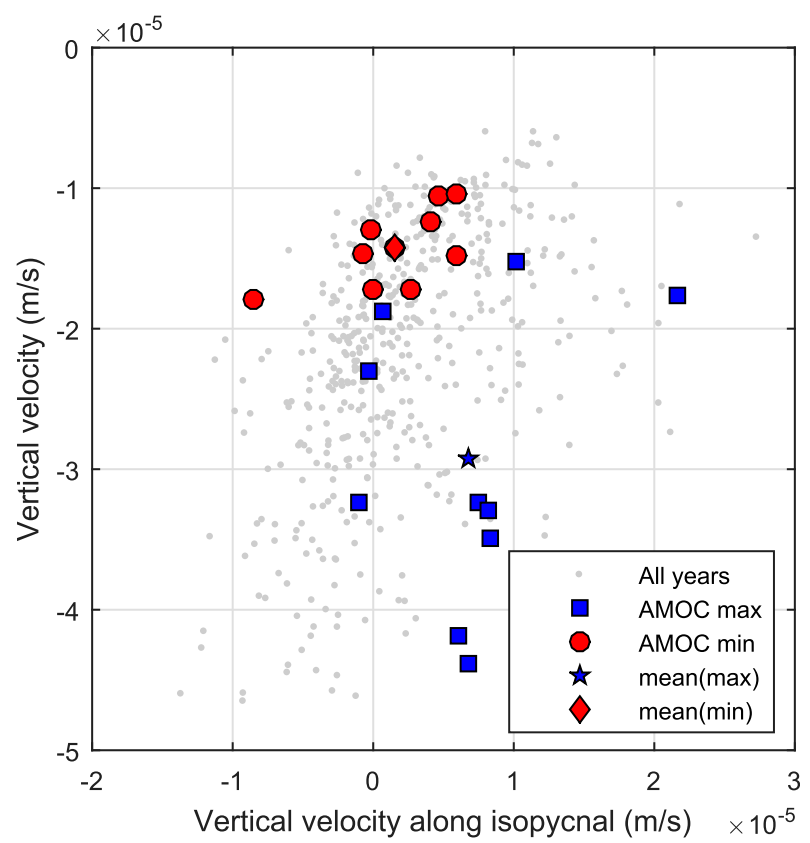

FIG. 7. Total vertical velocity, and the component along isopycnal [given by $u(\partial \rho / \partial x) /(\partial \rho / \partial z)+v(\partial \rho / \partial y) /(\partial \rho / \partial z)$ ] for preindustrial control simulation, at the location of the maximum variation in vertical velocity at $1000 \mathrm{~m}$ depth, $45^{\circ} \mathrm{N}$ and $314^{\circ} \mathrm{E}$ (see Fig. 6a). Years corresponding to AMOC maxima and minima (from Fig. 3a) are shown, as well as the average over those years. Most of the variation in vertical velocity associated with AMOC variability is cross isopycnal.

as in Stouffer and Manabe (2003) may offset some of this increased stratification.

Finally, we consider the increase in AMOC variability at high latitudes in the $4 \times \mathrm{CO}_{2}$ simulation. Figure 8 shows composite maps of ocean temperature for the $4 \times \mathrm{CO}_{2}$ simulation, averaged over the upper $1000 \mathrm{~m}$ from 7 years before to 8 years after an AMOC minimum. The time evolution of the spatial pattern of upper ocean heat content anomalies in this case is suggestive of advection by the subpolar gyre (local maxima and minima "rotate" about the center of the gyre). The corresponding plot for the preindustrial control simulation is shown in Fig. S3 in the supplemental material. An advection time scale for the subpolar gyre can be estimated by (i) selecting the location of minimum (or maximum) upper ocean heat content anomalies in each year of the lagged composite in Fig. 8, and (ii) calculating mean upper 1000$\mathrm{m}$ ocean currents at these locations. The resulting roughly $1 \mathrm{~cm} \mathrm{~s}^{-1}$ average currents in the $4 \times \mathrm{CO}_{2}$ case lead to an estimated 12-15-yr advection time around the gyre, roughly consistent with the time scale of the AMOC variability for this simulation (Fig. 2c). This suggests that the advection of anomalies in the subpolar gyre is strongly coupled with (possibly even causing) the AMOC variability at $60^{\circ} \mathrm{N}$ in the $4 \times \mathrm{CO}_{2}$ simulation, but decoupled from the weaker AMOC variability south of $50^{\circ} \mathrm{N}$. In the preindustrial simulation, the subpolar gyre circulation is roughly twice as strong (estimated either from ocean currents at the same locations, or from the barotropic streamfunction). There is thus a large separation of time scales between the subpolar advection and AMOC variability, as the stronger subpolar gyre circulation is characterized by twice shorter advection time scale. We conclude that the AMOC variability at $60^{\circ} \mathrm{N}$ in the $4 \times \mathrm{CO}_{2}$ case is likely linked to subpolar-gyre advection, as found in control simulations of CCSM3 and GFDL CM2.1 (Tulloch and Marshall 2012); however, this advection does not play a significant role in midlatitude AMOC variability in the $1 \times \mathrm{CO}_{2}$ simulation.

While the AMOC variability at $60^{\circ} \mathrm{N}$ in the $4 \times \mathrm{CO}_{2}$ case has a relatively small impact on midlatitude meridional heat transport, it can have a significant effect on climate via its link to the variability in sea ice concentration; Fig. S4 in the supplemental material shows the composite of annual-maximum sea ice extent. We find that salinity variations caused by the variations in sea ice concentration have only a small impact on ocean density and stratification relative to the temperature variations. The sea ice may be passively following the thermal variability, it might also play a dynamical role in the high-latitude AMOC variability at $4 \times \mathrm{CO}_{2}$ in this model through modulating air-sea heat exchange.

\section{Conclusions}

There has been significant research toward understanding the role of the AMOC in multidecadal climate variability using models and data. We focus here on a specific mechanism that can lead to a significant change in this variability under future increased $\mathrm{CO}_{2}$, as demonstrated by a particular model, GFDL ESM2M. We show that midlatitude AMOC oscillations present in the preindustrial simulation are largely absent in the $4 \times \mathrm{CO}_{2}$ scenario, in which the variability is located farther north near $60^{\circ} \mathrm{N}$ and involves changes to the northernmost extent of the MOC cell rather than changes to its maximum amplitude at midlatitudes. Transfer function analysis demonstrates that the differences in AMOC variability between the simulations are due to shifts in internal ocean dynamics, rather than in atmospheric forcing. Specifically, we find that the reduction in midlatitude AMOC variability is due to an increased 

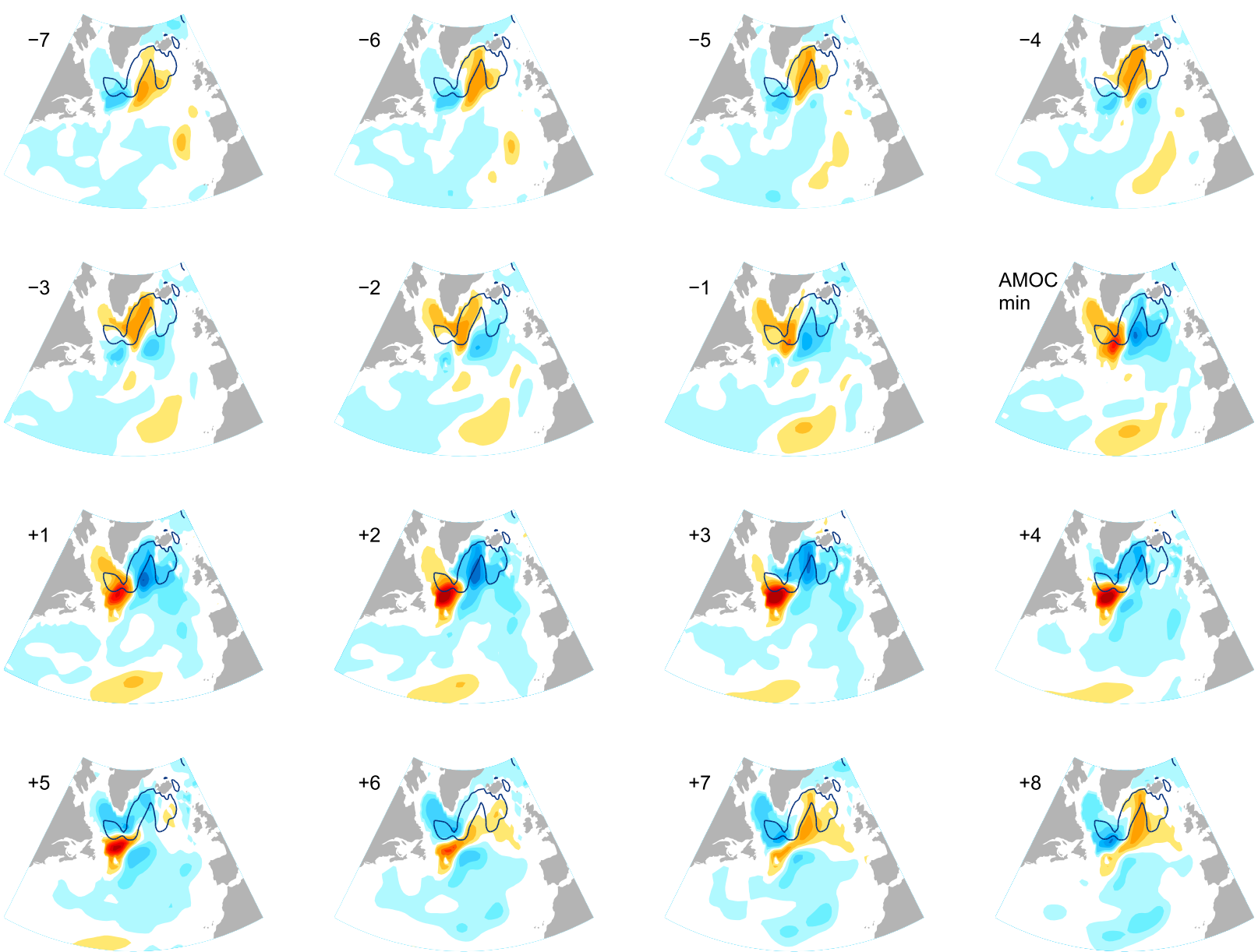

FIG. 8. Composite maps of the evolution of upper ocean heat content anomaly in the $4 \times \mathrm{CO}_{2}$ simulation. "AMOC min" shows the heat content averaged over AMOC minima (similar to Fig. 3f), while the remaining panels show the evolution prior to and after a minimum on the same color scale. The oscillation is less regular than for the preindustrial simulation; panel " +8 " is similar to the heat content averaged over AMOC maxima. One contour of the barotropic streamfunction is added to illustrate that the maxima and minima of the heat content are advected by the subpolar gyre.

stratification that is itself linked to a weaker and shallower mean AMOC under the higher $\mathrm{CO}_{2}$.

We find that a high-latitude spectral peak in AMOC variability at $4 \times \mathrm{CO}_{2}$ likely arises from a different mechanism from that in the preindustrial control, involving the advection of anomalies by the subpolar gyre. This result suggests that monitoring the subpolar gyre, as proposed by the Overturning in the Subpolar North Atlantic Program (OSNAP), might be key in understanding and predicting high-latitude climate variability under climate change.

Our findings are not consistent with the prediction of simple MOC models according to which a weaker overturning circulation brings the circulation closer to a bifurcation point at which the AMOC becomes unstable, which would have implied a larger variability as the mean circulation weakens under a greenhouse scenario. It is unclear whether this is a result of the $300-y r 4 \times \mathrm{CO}_{2}$ simulation used here still being in a transient state; box models have also typically been forced with freshwater rather than thermal forcing. Further work using a hierarchical modeling approach and additional GCMs would be valuable to put these results in perspective.

Acknowledgments. DGM and ET were supported by NOAA Awards NA13OAR4310129 and NA13OAR4310130, respectively, and by DOE Award DE-SC004984; LZ was supported by NERC Grant NE/K013548/1. We thank the GFDL climate modeling group for producing and making available their model output. ET thanks the Weizmann institute for its hospitality during parts of this work. DGM thanks the Carnegie Institution for its hospitality during parts of this work. 


\section{REFERENCES}

Bryan, K., 1982: Poleward heat transport by the ocean: Observations and models. Annu. Rev. Earth Planet. Sci., 10, 15-38, doi:10.1146/annurev.ea.10.050182.000311.

Buckley, M. W., and J. Marshall, 2016: Observations, inferences, and mechanisms of the Atlantic Meridional Overturning Circulation: A review. Rev. Geophys., 54, 5-63, doi:10.1002/ 2015RG000493.

Cheng, W., J. C. H. Chiang, and D. Zhang, 2013: Atlantic meridional overturning circulation (AMOC) in CMIP5 models: RCP and historical simulations. J. Climate, 26, 7187-7197, doi:10.1175/ JCLI-D-12-00496.1.

Collins, M., and Coauthors, 2013: Long-term climate change: Projections, commitments and irreversibility. Climate Change 2013: The Physical Science Basis, T. F. Stocker et al., Eds., Cambridge University Press, 1029-1136.

Cunningham, S. A., and Coauthors, 2007: Temporal variability of the Atlantic meridional overturning circulation at $26.5^{\circ} \mathrm{N}$. Science, 317, 935-938, doi:10.1126/science.1141304.

Delworth, T., and M. E. Mann, 2000: Observed and simulated multidecadal variability in the Northern Hemisphere. Climate Dyn., 16, 661-676, doi:10.1007/s003820000075.

_ , S. Manabe, and R. J. Stouffer, 1993: Interdecadal variations of the thermohaline circulation in a coupled ocean-atmosphere model. J. Climate, 6, 1993-2011, doi:10.1175/1520-0442(1993)006<1993: IVOTTC $>2.0 . \mathrm{CO} ; 2$

Ditlevsen, P. D., and S. J. Johnsen, 2010: Tipping points: Early warning and wishful thinking. Geophys. Res. Lett., 37, L19703, doi:10.1029/2010GL044486.

Dunne, J. P., and Coauthors, 2012: GFDL's ESM2 global coupled climate-carbon Earth system models. Part I: Physical formulation and baseline simulation characteristics. J. Climate, 25, 6646-6665, doi:10.1175/JCLI-D-11-00560.1.

Greatbatch, R. J., and S. Zhang, 1995: An interdecadal oscillation in an idealized ocean basin forced by constant heat flux. J. Climate, 8, 81-91, doi:10.1175/1520-0442(1995)008<0081: AIOIAI $>2.0 . \mathrm{CO} ; 2$

Gregory, J. M., and Coauthors, 2005: A model intercomparison of changes in the Atlantic thermohaline circulation in response to increasing atmospheric $\mathrm{CO}_{2}$ concentration. Geophys. Res. Lett., 32, L12703, doi:10.1029/2005GL023209.

Griffies, S. M., and E. Tziperman, 1995: A linear thermohaline oscillator driven by stochastic atmospheric forcing. J. Climate, 8, 2440-2453, doi:10.1175/1520-0442(1995)008<2440:ALTODB>2.0.CO;2.

— decadal climate variability. Science, 275, 181-184, doi:10.1126/ science.275.5297.181.

Hirschi, J. J.-M., and J. Marotzke, 2007: Reconstructing the meridional overturning circulation from boundary densities and the zonal wind stress. J. Phys. Oceanogr., 37, 743-763, doi:10.1175/JPO3019.1.

Johns, W. E., and Coauthors, 2011: Continuous, array-based estimates of Atlantic Ocean heat transport at $26.5^{\circ}$ N. J. Climate, 24, 2429-2449, doi:10.1175/2010JCLI3997.1.

Knight, J. R., R. J. Allan, C. K. Folland, M. Vellinga, and M. E. Mann, 2005: A signature of persistent natural thermohaline circulation cycles in observed climate. Geophys. Res. Lett., 32, L20708, doi:10.1029/2005GL024233.

Kushnir, Y., 1994: Interdecadal variations in North Atlantic sea surface temperature and associated atmospheric conditions. J. Climate, 7, 141-157, doi:10.1175/1520-0442(1994)007<0141: IVINAS $>2.0 . \mathrm{CO} ;$.
Lenton, T. M., 2011: Early warning of climate tipping points. Nat. Climate Change, 1, 201-209, doi:10.1038/nclimate1143.

_ , V. N. Livina, V. Dakos, E. H. van Nes, and M. Scheffer, 2012: Early warning of climate tipping points from critical slowing down: Comparing methods to improve robustness. Philos. Trans. Roy. Soc. London, 370A, 1185-1204, doi:10.1098/ rsta.2011.0304.

MacMartin, D. G., E. Tziperman, and L. Zanna, 2013: Frequencydomain multimodel analysis of the response of Atlantic meridional overturning circulation to ocean surface forcing. J. Climate, 26, 8323-8340, doi:10.1175/JCLI-D-12-00717.1.

MacMynowski, D. G., and E. Tziperman, 2010: Testing and improving ENSO models by process using transfer functions Geophys. Res. Lett., 37, L19701, doi:10.1029/2010GL044050.

McCarthy, G., and Coauthors, 2012: Observed interannual variability of the Atlantic meridional overturning circulation at $26.5^{\circ}$ N. Geophys. Res. Lett., 39, L19609, doi:10.1029/ 2012 GL052933.

Msadek, R., K. W. Dixon, T. L. Delworth, and W. Hurlin, 2010: Assessing the predictability of the Atlantic meridional overturning circulation and associated fingerprints. Geophys. Res. Lett., 37, L19608, doi:10.1029/2010GL044517.

Muir, L. C., and A. V. Fedorov, 2015: How the AMOC affects ocean temperatures on decadal to centennial timescales: The North Atlantic versus an interhemispheric seesaw. Climate Dyn., 45, 151-160, doi:10.1007/s00382-014-2443-7.

O'Reilly, C. H., M. Huber, T. Woollings, and L. Zanna, 2016: The signature of low-frequency oceanic forcing in the Atlantic Multidecadal Oscillation. Geophys. Res. Lett., 43, 2810-2818, doi:10.1002/2016GL067925.

Stocker, T. F., and A. Schmittner, 1997: Influence of $\mathrm{CO}_{2}$ emission rates on the stability of the thermohaline circulation. Nature, 388, 862-865, doi:10.1038/42224.

Stommel, H., 1961: Thermohaline convection with two stable regimes of flow. Tellus, 13A, 224-230, doi:10.1111/ j.2153-3490.1961.tb00079.x.

Stouffer, R. J., and S. Manabe, 2003: Equilibrium response of thermohaline circulation to large changes in atmospheric $\mathrm{CO}_{2}$ concentrations. Climate Dyn., 20, 759-773, doi:10.1007/ s00382-002-0302-4.

te Raa, L., J. Gerrits, and H. A. Dijkstra, 2004: Identification of the mechanism of interdecadal variability in the North Atlantic Ocean. J. Phys. Oceanogr., 34, 2792-2807, doi:10.1175/ JPO2655.1.

Tulloch, R., and J. Marshall, 2012: Exploring mechanisms of variability and predictability of Atlantic meridional overturning circulation in two coupled climate models. J. Climate, 25, 4067-4080, doi:10.1175/JCLI-D-11-00460.1.

Tziperman, E., 1997: Inherently unstable climate behaviour due to weak thermohaline ocean circulation. Nature, 386, 592-595, doi:10.1038/386592a0.

__ J. R. Toggweiler, Y. Feliks, and K. Bryan, 1994: Instability of the thermohaline circulation with respect to mixed boundary-conditions: Is it really a problem for realistic models? J. Phys. Oceanogr., 24, 217-232, doi:10.1175/ 1520-0485(1994)024<0217:IOTTCW>2.0.CO;2.

Wiesenfeld, K., and B. McNamara, 1986: Small-signal amplification in bifurcating dynamical systems. Phys. Rev., 33A 629-642, doi:10.1103/PhysRevA.33.629.

Yeager, S., and G. Danabasoglu, 2012: Sensitivity of Atlantic meridional overturning circulation variability to parameterized Nordic sea overflows in CCSM4. J. Climate, 25, 2077-2103, doi:10.1175/JCLI-D-11-00149.1. 